UDC: 57.082.15:616-006.484:591.481.1:591.882:616-092.9

Liubich L. D., Lisyany N. I., Semenova V. M., Stayno L. P.

A. P. Romodanov State Institute of Neurosurgery NAMS of Ukraine, Kyiv, Ukraine

e-mail: lyubichld@gmail.com

\title{
DYNAMICS OF CD133+ CELLS IN CULTURES OF GLIOMA C6 AND FETAL RAT BRAIN UNDER THE NEUROGENIC CELLS SUPERNATANT INFLUENCE
}

\section{ABSTRACT}

Cellular and molecular similarities between brain tumor stem cells (BTSCs) and normal neurogenic stem cells (NSCs) motivate the search for new methods of treatment of malignant glioma using NSCs. CD133 molecule could be one of the most typical markers of BTSCs and considered as a target for therapy of brain tumors.

The aim of this study was to evaluate the effect of rat neurogenic cells supernatant (NCSS) on the content of CD133+ cells in glioma C6 cell cultures.

MATERIALS AND METHODS. The cells of rat brain glioma C6 were used as the source for the cultivation; for comparative assessment of tested compound impact on the intact nervous system the fetal rat brain cells on 14th (E14) day of gestation were used.

The study was performed in control cultures under standard culture conditions without NCsS adding and tested cultures with adding NCsS (0.10 $\mathrm{mg} / \mathrm{ml}$ of protein) for 48 hours. NCSS was received from suspensions of rat brain neurogenic cells (E14).

RESULTS. CD133-positive cells were $12.05 \pm 4.77 \%$ of the total number of cells in C6 glioma culture and $37.36 \pm 12.33 \%$ of the total number of cells in fetal rat brain culture. CD133-positive cells had a smaller size than negative cells (average values of cross-sectional area of cells and nucleus) and greater nuclear-cytoplasmic ratio. The cell and nucleus sizes of CD133-positive cells in cell cultures of fetal rat brain were twice larger than sizes of such cells in cultures of glioma C6.

Under the conditions of NCSS for 48 hours the reducing in the number of CD133-positive cells in rat glioma C6 cell cultures (2.88 $\pm 0.41 \%)$ and lack of such effects in cell cultures of fetal rat brain (E14) were found.

CONCLUSION. The morphological differences of CD133-positive cells in glioma C6 cultures and in cell cultures of fetal rat brain (E14) were detected. The decrease of CD133-positive cells in glioma C6 cells culture under the influence of neurogenic cells supernatant was shown.

KEYWORDS: glioma C6, fetal rat brain cell culture, neurogenic cells supernatant, CD133

Active studies of biological properties of neurogenic stem cells (NSCs) and the discovery of brain tumor stem cells (BTSCs) excite review the problem of the origin and progression of tumors. Cellular and molecular similarities between BTSCs and normal NSCs justify the search for new treatments using NSCs at malignant gliomas.

The brain tumors, especially the most malignant glioma forms glioblastomas, contain subpopulations of BTSCs or tumor initiating cells that cause resistance of tumors to radiation and chemotherapy [1, 2]. Both BTSCs and NSCs have clonogenic properties, form neurospheres in the culture, and express neuronal and astroglial markers during differentiation. It is believed that NSCs of subventricular zone are the most probable source of gliomas by the impact of carcinogens or oncogenic viruses [3] and they are responsible for recurrence of disease after surgical resection. BTSCs and NSCs have the ability to self-renewal and multiple drug resistance $[4,5]$. The latter property is associated with an increased expression and activity of ABC-transporters, which are common BTSCs and NSCs markers. Another common marker is a cell surface protein CD133 (prominin-1) [6, 7].

CD133 was first identified in the protrusions of membranes of murine neuroepithelial stem cells (SCs). The molecule CD133 belongs to the family of cell surface glycoproteins with five transmembrane domains and is found in both normal cells and a number of different types of tumor and cancer cells. In epithelial cells, especially in neuroepithelial SCs, CD133 is localized in the microvilli, primary cilia and the middle part of the cell body; 
filopodia and lamellipodia of the apical surface of neural epithelial cells [7]. These types of cell surface membrane are exposed to remodulation while epithelial and neuroepithelial cell differentiation. CD133 may play a key role in organizing of the apical plasma membrane in epithelial cells. It is known that excessive expression of glycoprotein occurs at acute myeloid leukaemia, acute and chronic lymphocytic leukaemia, myelodysplastic syndrome, retinoblastomas, kidney carcinomas and glioblastomas. High levels of CD133 are also detected in tumors of the pancreas, stomach, colorectal and hepatocellular cancers, breast cancer, melanoma, osteosarcoma [1, 2]. It is believed that CD133 may be one of the most typical markers of BTSCs and can be considered as a target for therapy of brain tumors [1].

At the same time there was shown the potential of NSCs or neurogenic progenitor cells (NPCs) as anticancer agents in the development of gene-cell therapy of malignant gliomas of the brain due to migration and integration into pathological niches in the central nervous system [8-13]. In the previous studies in different model systems we demonstrated some aspects of antitumor properties of neurogenic fetal brain cells and, in particular, humoral factors produced by them $[14,15]$.

The aim of this study was to investigate the effect of rat neurogenic cells supernatant (NCsS), as a source of humoral factors, on the content of $\mathrm{CD} 133^{+}$cells in rat glioma $\mathrm{C} 6$ cultures.

\section{MATERIALS AND METHODS}

As a material for the culture there were used cells of rat brain glioma C6 from Cell bank of human and animals tissue lines, R. E. Kavetsky Institute of Experimental Pathology, Oncology and Radiobiology, NAS of Ukraine $(n=6)$. For a comparative assessment of the impact of the studied compound on intact neural cells we used cells of fetal rat brain on the $14^{\text {th }}$ day of gestation (E14) $(n=6)$. The studies were conducted in the following groups: 1) control cultures - under standard culture conditions without NCsS; 2) tested cultures - under of NCsS impact $(0.10 \mathrm{mg} / \mathrm{ml}$ of protein) for 48 hours.

All the studies with experimental animals were conducted in compliance with the Law of Ukraine «On protection of animals from cruelty», «European Convention for the protection of vertebrate animals used for experimental and other scientific purposes» in accordance with the principles of bioethics and norms of biosafety and agreed by the Committee on bioethics A. P. Romodanov State Institute of Neurosurgery, NAMS of Ukraine. The animals were kept in standard conditions of vivarium, euthanasia were performed under ether anaesthesia.

The cells of fetal rat brain (E14) were received by protocol [16]. In the study we used white rats $(n=6$, females, weight $200+10 \mathrm{~g})$ from the vivarium of A. P. Romodanov State Institute of Neurosurgery, NAMS of Ukraine. Fetuses were removed from anesthetized pregnant rats on $14 \mathrm{dpc}$ under sterile conditions and placed in Petri dishes in the DMEM medium (Sigma-Aldrich $\mathrm{GmbH}$, Germany). Brain tissue was isolated, washed in DMEM medium, freed of vessels and membranes, transferred into fresh medium and mechanically dissociated by repeated pipetting. The cells were pelleted by centrifugation for $5 \mathrm{~min}$ at $1500 \mathrm{rpm}$, washed in DMEM medium, fresh DMEM medium was added and resuspended. The viability of cells in suspension was determined by the permeability of plasma membrane for $0.2 \%$ trypan blue (Merch, Germany) [16].

To obtain primary cultures the cells of glioma $\mathrm{C} 6$ and cells of fetal rat brain (E14) in the amount $1 \cdot 10^{6}$ were applied on adhesive coating coverglasses coated with polyethylenimine (Sigma-Aldrich $\mathrm{GmbH}$, Germany), which were placed in Petri dishes and cultured in medium 199 and DMEM (1:1) supplemented with $10 \%$ fetal calf serum, 400 $\mathrm{mg} \%$ glucose and $0.2 \mathrm{U} / \mathrm{ml}$ insulin. The cell cultures were kept in $\mathrm{CO}_{2}$ incubator $\left(37{ }^{\circ} \mathrm{C}, 95 \%\right.$ humidity and $\left.5 \% \mathrm{CO}_{2}\right)$ and observed in vivo with inverted microscope Eclips TS 100 (Nikon, Japan) with microphoto registration.
The of neurogenic cell supernatant was received by culturing of rat brain neurogenic cells obtained on the $14^{\text {th }}$ (E14) day of gestation as previously described [14]. Native rat brain tissue was transferred to DMEM medium (Sigma-Aldrich $\mathrm{GmbH}$, Germany) and suspended by multiple pipetting. The cells were pelleted by centrifugation for $5 \mathrm{~min}$ at $1500 \mathrm{rev} / \mathrm{min}$, washed in DMEM medium, the cell pellet was added with fresh DMEM medium and resuspended. The concentration of cells was adjusted to $6 \cdot 10^{6} / \mathrm{ml}$, to the resulting cell suspension we added concanavalin $\mathrm{A}(0.1 \mathrm{mg} / \mathrm{ml})$ and incubated for 2 hours in a $\mathrm{CO}_{2}$ incubator at $37.0 \pm 0.5{ }^{\circ} \mathrm{C}$, constant humidity of $95 \%$ and $5 \% \mathrm{CO}_{2}$. After incubation, the cells were pelleted by centrifugation for 5 min at 1500 rpm, washed in DMEM medium, cells pellet was added with fresh DMEM medium, resuspended and incubated for $24 \mathrm{~h}$. After incubation, the cells were pelleted once more by centrifugation for $5 \mathrm{~min}$ at $1500 \mathrm{rpm}$, the supernatant was collected, its protein concentration was determined by the method of Lowry, standardized to a concentration of $1.0 \mathrm{mg} / \mathrm{ml}$, aliquoted and stored at $-20 \pm 0.5^{\circ} \mathrm{C}$

For the study of NCsS effects on primary cultures we selected the cultures with a proportional growth area, added NCsS $(0.10 \mathrm{mg} / \mathrm{ml}$ of protein) and incubated for 48 hours. Cultures were fixed in $10 \%$ formalin and cytological and immunohistochemical analysis of cell composition was performed.

Immunofluorescent staining for CD133 was performed using mouse monoclonal antibody to CD133 (Millipore, USA). Cell cultures, fixed on glass slides, were transferred into a solution of $0.01 \mathrm{M}$ phosphate buffer ( $\mathrm{pH} \mathrm{6.0)}$ for $5 \mathrm{~min}$. To block non-specific background staining the coverglasses with cultures were incubated for 10 minutes with a reagent Ultra V block (Thermo Scientific, USA). After washing in the buffer for 5 min murine monoclonal antibodies to CD133 were added on the coverglasses with the cultures (Millipore, USA) at a dilution of 1:100 and incubated for $60 \mathrm{~min}$ at room temperature. After washing in the buffer the coverglasses with the cultures were stained with FITC-labelled rabbit antibodies to mouse IgG (Sorbent, Russia) in a dilution of 1:500 and incubated for $20 \mathrm{~min}$ at room temperature. After that they were washed with distilled water and analysed. Simultaneously we conducted studies with positive and negative controls.

Microscopic examination and photo registration of cytological samples of primary cultures were performed on Axiolmager A2 microscope (Carl Zeiss Microscopy GmbH, Germany) with a broadband filter and camera AxioCam MRc5 (Carl Zeiss Microscopy GmbH, Germany). The quantitative studies of control and experimental cultures were conducted in 10 representative fields of view with a standard micrometer scale. Digital image analysis was performed using the software Zen Lite 2012 (Germany). In cell culture samples we determined the total number of cells, a number of CD133-positive /negative cells and morphometric parameters.

Morphometric analysis was carried out using the digital processing of culture images in 10 randomly selected fields of view $\left(0.04 \mathrm{~mm}^{2}\right)$ for each sample at the same magnification $\times 800$. There we determined: the number of cells per $0.04 \mathrm{~mm}^{2}$ of the culture sample; cross-sectional area of nuclei in the sample per $0.04 \mathrm{~mm}^{2}$ culture; cross-sectional area of the cell cytoplasm per $0.04 \mathrm{~mm}^{2}$ of sample culture; the length of the processes. The quantitative index of nucleo-cytoplasmic ratio was found as a mathematical proportion of cross-section area of nuclei by crosssectional area of the cells cytoplasm.

The number of CD133-positive and negative cells was determined in 10 randomly selected fields of view for each sample at the same magnification $x 800$ and calculated as a share of the total number of cells in percent.

Statistical data processing was performed using the Statistica 6.0 software (StatSoft Inc., 2003). We used parametric (Student's t-test, double-selective t-test with different dispersions) and nonparametric (Mann-Whitney test for comparison of independent groups) methods of variation statistics. Normality of data distribution was determined by the Shapiro-Wilk test. A statistically significant difference was considered when $p<0.05$, statistically highly significant at $p<0.01$. 


\section{RESULTS AND DISCUSSION}

To investigate the influence of NCsS cell cultures with a proportional growth area were selected on $7-10^{\text {th }}$ day. In control glioma C6 cultures we determined tumor cells of astrocytic phenotype with unipolar, triangular or rhomboid shape with processes (average length $91.39 \pm 11.91 \mu \mathrm{M}$ ), which formed the reticular structure (fig. 1a).

CD133-positive tumor cells amount to $12.05 \pm 4.77 \%$ of the total number of cells in culture (Fig. 2). These results are generally consistent with previous findings in the literature [1].

CD133-positive tumor cells were considerably smaller, compared to the negative cells: their morphometric parameters significantly differed. In particular, the average value of cross-sectional area of CD133 negative and positive cells were $1284.23 \pm 199.66 \mu \mathrm{m}^{2}$ and $222.43 \pm 23.91 \mu \mathrm{m}^{2}$, respectively $(p<0.01$, Mann -Whitney U-test, fig. 3a); average values of cross-sectional area of the nucleus of CD133-negative cells (193.35 \pm $\left.30.88 \mu \mathrm{m}^{2}\right)$ exceeded the corresponding values of positive cells $(52.97 \pm$ $6.87 \mu \mathrm{m}^{2}, \mathrm{p}<0.01$, fig. $3 \mathrm{~b}$ ); nucleo-cytoplasmic ratio in CD133-positive cells $0.51 \pm 0.10$ was higher than the rate in CD133- negative cells $(0.18$ $\pm 0.02, p<0.01$, fig. 3c)

In control cultures of intact cells of fetal rat brain (E14) reticular structures of glial cells with processes, including cells of neuroblast phenotype, formed (fig. 1c). The average length of processes was 69.24 $\pm 32.24 \mu \mathrm{m}$. The cells, positive for CD133, were $37.36 \pm 12.33 \%$ of the total number of cells in culture, which significantly exceeded the number of positive cells in glioma C6 culture $(p<0.01$, U-Mann-Whitney test, fig. 2). At the same time, morphometric parameters of CD133-positive cells in the cell culture of fetal rat brain (E14) as in the glioma C6 cell culture, highly statistically differed from that of CD133-negative cells. Thus, the average values of the cross-section area of CD133-negative and positive cells were respectively $1372.65 \pm 116.98 \mu \mathrm{m}^{2}$ and $417.87 \pm 62.80 \mu \mathrm{m}^{2}$ $(\mathrm{p}<0.01$, fig. 3); average values of cross-sectional area of the nuclei of CD133-negative cells $\left(156.34 \pm 9.04 \mu \mathrm{m}^{2}\right)$ exceeded the corresponding values of positive cells $\left(111.19 \pm 22.69 \mu \mathrm{m}^{2}, p<0.01\right.$, fig. $\left.3 \mathbf{b}\right)$; the nucleocytoplasmic ratio of CD133-positive cells $(0.35 \pm 0.02)$ exceeded the rate of CD133-negative cells $(0.14 \pm 0.02, p<0.01$, fig. 3c). However, the size of CD133-positive cells and their nuclei in cell cultures of fetal rat brain (E14) were significantly larger than the size of cells in glioma C6 cultures:
Fig. 2. CD133+ cells in culture under influence of NCsS $(0.1 \mathrm{mg} / \mathrm{ml}, 48 \mathrm{~h})$

\section{$\%$ \\ Fraction of CD133+ cells, \%}

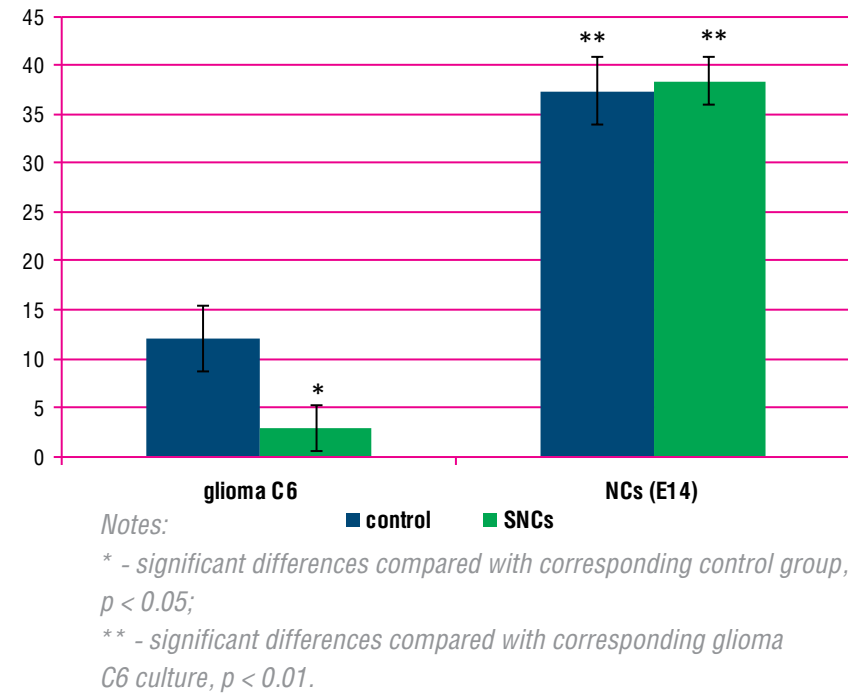

figures of the sectional area of a cell and a nucleus differed by almost half (respectively $222.43 \pm 23.91 \mu^{2}$ and $417.87 \pm 62.80 \mu \mathrm{m}^{2}, \mathrm{p}<0.01$; $52.97 \pm 6.87 \mu \mathrm{m}^{2}$ and $111.19 \pm 22.69 \mu \mathrm{m}^{2}, \mathrm{p}<0.01$, fig. $\left.\mathbf{3 a}, \mathbf{b}\right)$.

After 48 hours incubation of glioma C6 cultures with NCsS there appeared signs of degenerative or necrobiotic changes of tumor cells in the area of culture growth (Fig. 1b). The number of CD133-positive cells under the influence NCsS statistically significantly reduced to $2.88 \pm 0.41$ $\%, p<0.05$ compared with control (fig. 2, Fig. 4b).

In contrast, after the incubation of fetal rat brain (E14) cell cultures with NCsS the structure of the growth zone and cell types had no significant differences, compared with control (Fig. 1d), which may indicate a lack of significant NCsS effect on intact neural cells. The number of CD133positive cells under the influence of NCsS unchanged $(38.89 \pm 7.08 \%$, $\mathrm{p}=0.209$ compared with control) (fig. 2, fig. 4c, d).

Thus, the study of the influence of NCsS for 48 hours on cultured glioma C6 cells demonstrate decrease of CD133-positive cells, that is
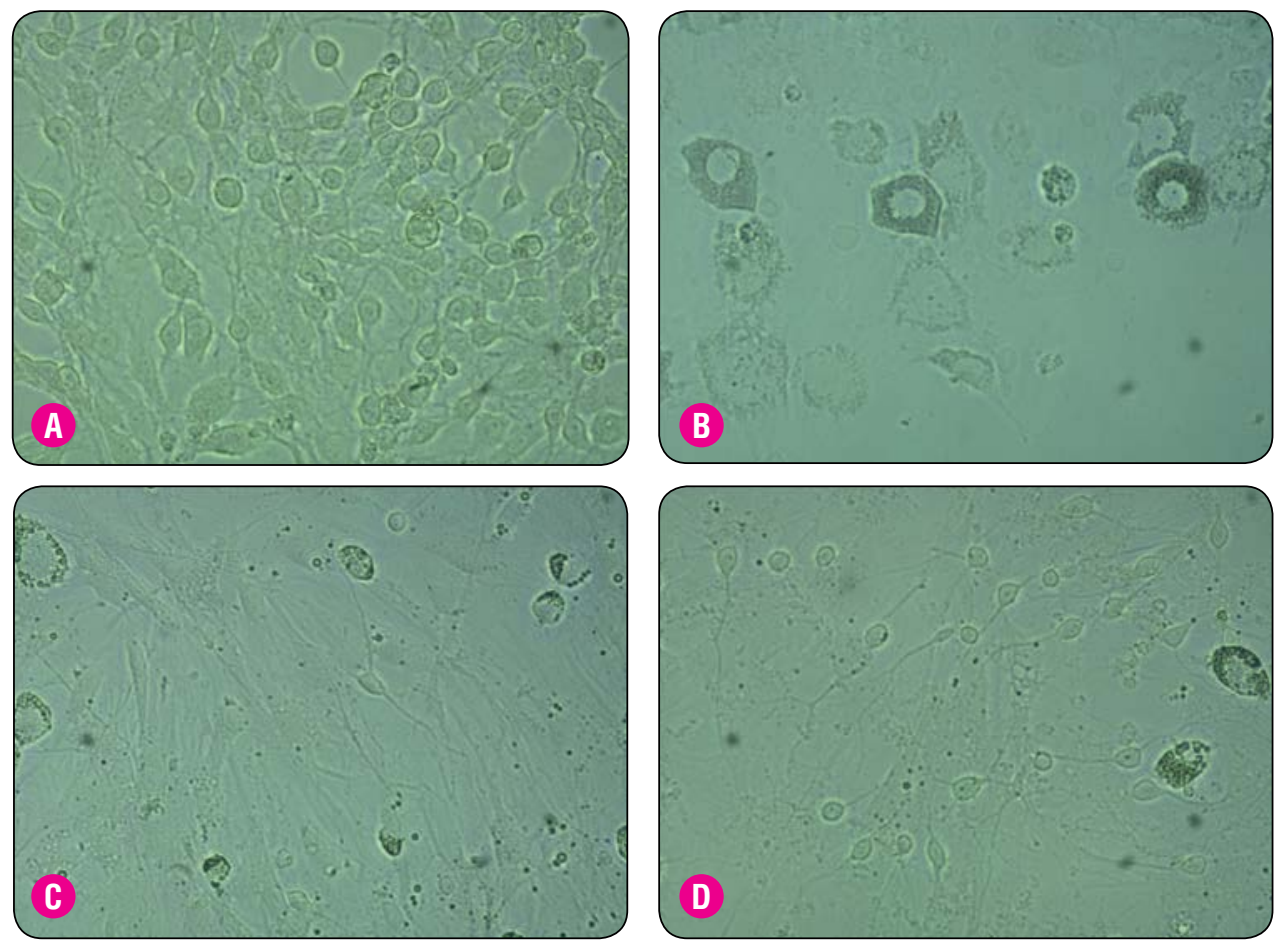

$<$

Fig. 1. Microphotographs

of primary cell cultures of glioma C6 and fetal rat brain. Morphological changes under the influence of fetal neurogenic cells supernatant (NCsS). Light microscopy, $\times 800$. a - glioma C6 culture, 7th day, control

b - glioma C6 culture, incubation with NCsS (E14), $0.10 \mathrm{mg} / \mathrm{ml}$, 48 hours.

c - culture of fetal rat brain (E14), 10th day, control.

d - culture of fetal rat brain (E14), incubation with NCsS (E14), 0.10 $\mathrm{mg} / \mathrm{ml}, 48$ hours. 
Fig. 3. Morphological characteristics of cultured cells based on the expression of CD133.

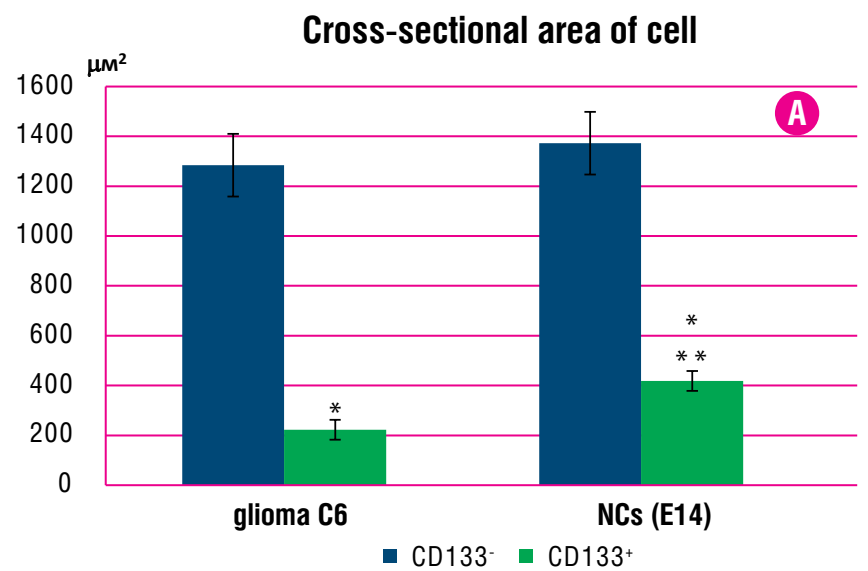

BTSCs in tumor cells culture. Such effect on CD133-expressing cells in the culture of fetal rat brain was not found, but there was twice smaller size of CD133-positive cells in cultures of glioma C6, compared to CD133positive cells of fetal brain. Therefore, it can be assumed that BTSCs of glioma C6 are qualitatively different from NSCs (probably they express ligands for the active molecular agents that are part of NCsS).

In this regard, in our opinion, it is necessary to provide the data of Chen et al. research (2010) [17], who demonstrated the simultaneous existence of three different types of BTSCs in glioma tissue, characterized by expression of CD133: 1) CD133-negative cells, capable of generating CD133-positive progenitors; 2) CD133-positive cells, capable of generating CD133-negative cells; 3) CD133-negative cells that generate only CD133negative progenitors. Therefore, some authors are slightly criticizing the role of CD133 as a marker of SCs because of unexplained biological function [2].

It should be noted that at present particular ligands or CD133 molecules with cell signaling pathways are unidentified. According to Angelastro J. M. and Lame M. W. (2010), exogenous expression of CD133 caused a decrease in tumor cells apoptosis by 2-4 times in response to therapeutic agents such as doxorubicin and captotecin and $\mathrm{CD}_{133^{+}}$ glioma $\mathrm{C} 6$ cells had increased by $62 \%$ expression of one $\mathrm{ABC}$-transporter (P-glycoprotein) that led to the drug resistance. The authors support
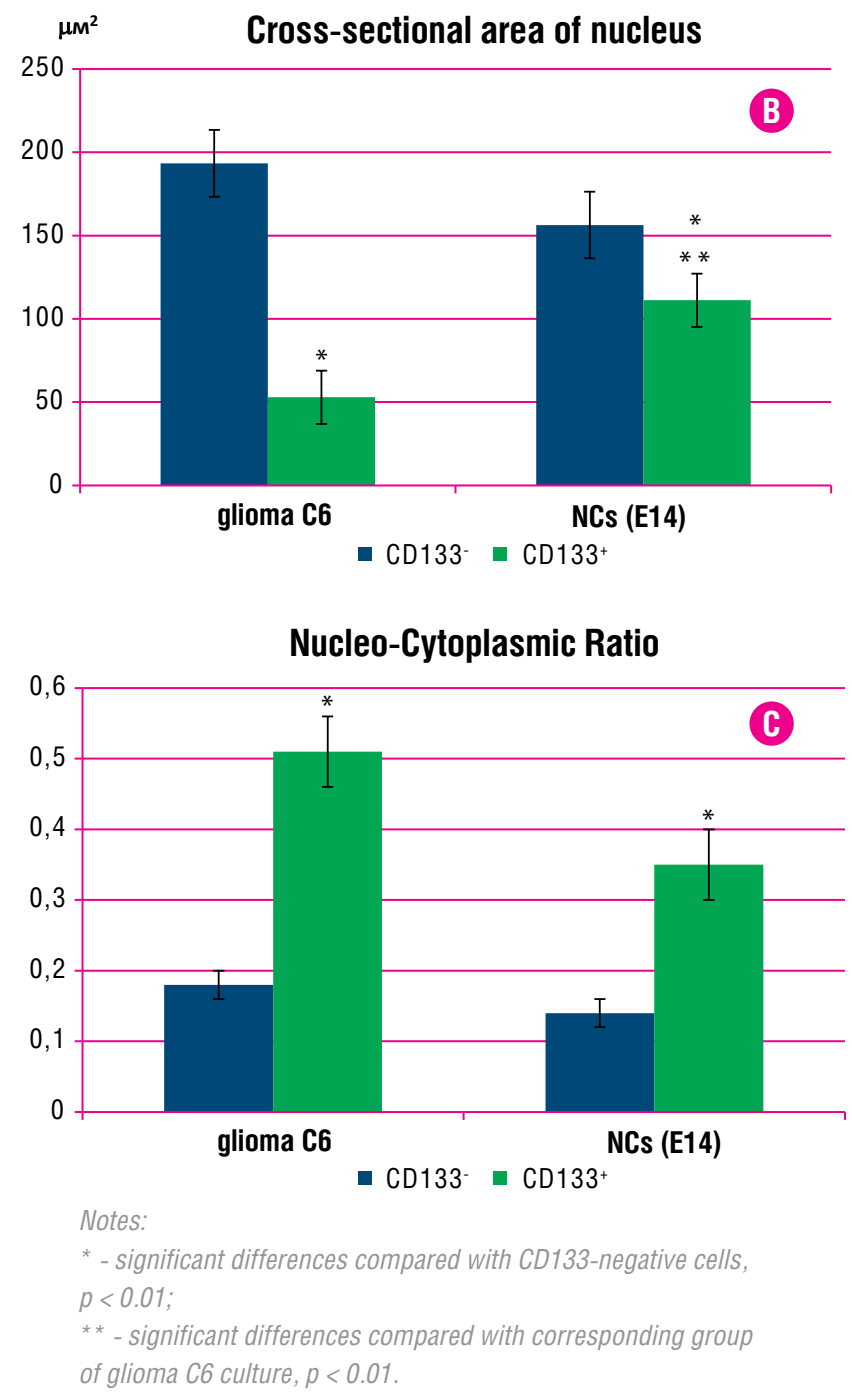
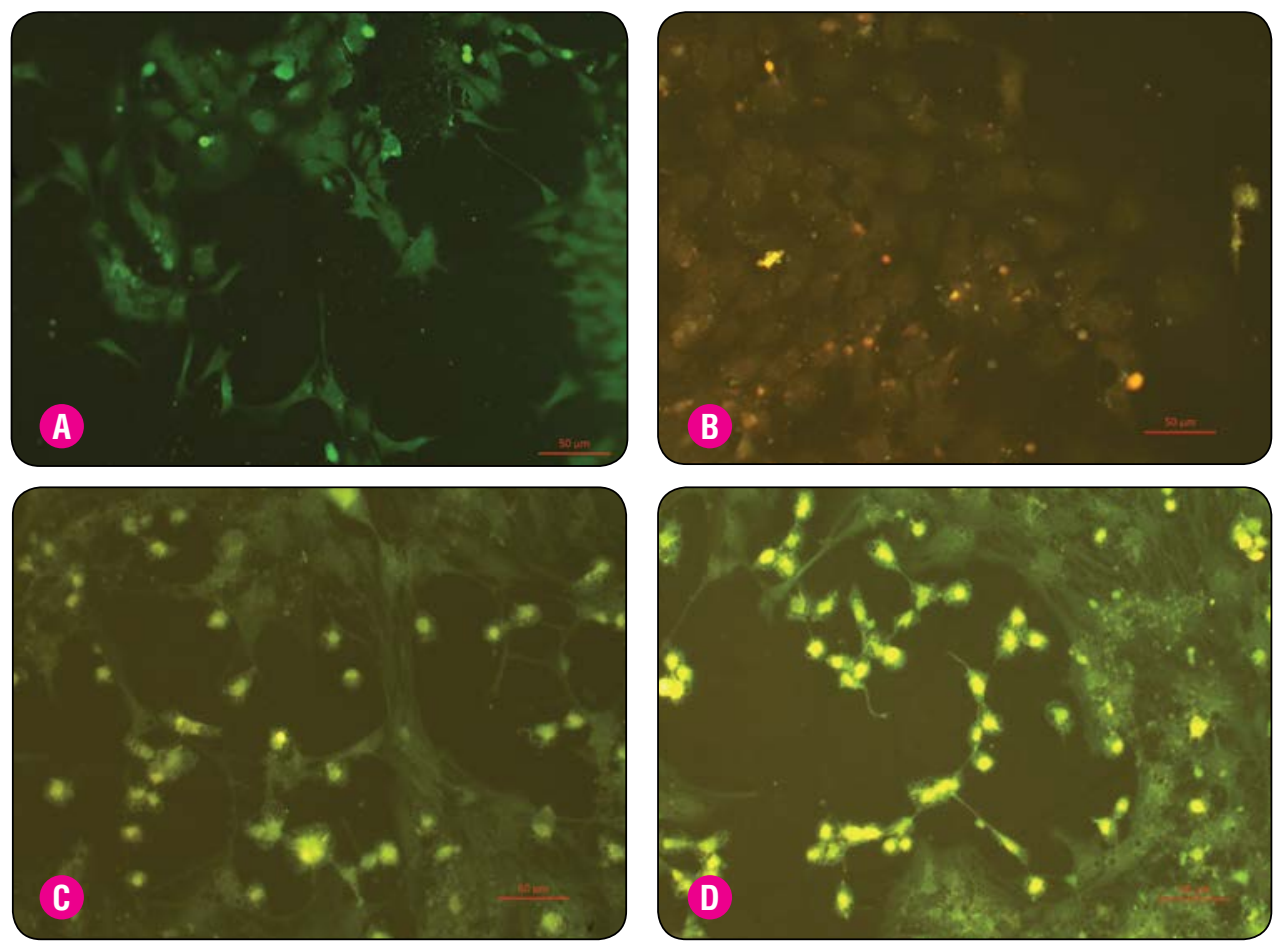

Fig. 4. Microphotographs of glioma C6 and fetal brain cell culture. Morphological changes under the influence of fetal neurogenic cells supernatant (NCsS).

Immunofluorescent staining for CD133 (green). Luminescence microscopy.

a - glioma C6 culture, control;

b - glioma C6 culture, incubation with NCsS (E14), $0.10 \mathrm{mg} / \mathrm{ml}, 48 \mathrm{~h}$;

c - fetal brain cell culture, control;

d - fetal brain cell culture, incubation with NCsS (E14), $0.10 \mathrm{mg} / \mathrm{ml}, 48$ hours. 
the hypothesis of anti-apoptotic functional role of CD133 in protecting tumor cells from chemotherapeutic drugs.

According to our previous studies, NCsS of rats contains two main prevailing factions of proteins: $67 \mathrm{kDa}-55 \% ; 46 \mathrm{kDa}-44 \%$; and minor fractions with small amounts of BDNF, BDNF, TGF- $\beta 1$, IL-1 $\beta$, IL-4 [15]. This is consistent with known data that multipotent human, rat and mouse neural progenitor cells can express both proinflammatory and suppressor cytokines (IL-1 a, IL-1 $\beta$, IL-6, IL-10, TGF- $\beta 1$, TGF- $\beta 2$, TNF- $\alpha$, LIF) [18-20]. In our opinion, decrease of CD133-expressing cells (BTSCs) number in glioma $\mathrm{C} 6$ cell culture under the NCsS influence is caused by TGF- $\beta 1$ effects (regulation of proliferation, differentiation and survival/apoptosis of cells) [21-23] and, possibly, BDNF (binding with receptors of tumor necrosis superfamily factor that activate intracellular signaling cascades (NF-kB, Jun-kinase) that mediate the initiation of apoptosis [24].

The mechanism of NCsS influence on CD133 expression in glioma C6 cells requires further study. Because CD133 is considered as critical target for therapy of brain tumors, obtained results can be the basis for a comprehensive study of preparations with fetal neurogenic cells for theoretical justification of their use in pathogenetic treatment of patients with gliomas.

\section{CONCLUSIONS}

CD133-positive cells in glioma C6 cultures were twice smaller than CD133-positive cells in the cell cultures of fetal rat brain (E14). Under the conditions of NCsS action at a concentration of $0.1 \mathrm{mg} / \mathrm{ml}$ for 48 hours there was reducing of CD133-positive cells in rat glioma C6 cell culture and the lack of such influence in cell culture of fetal rat brain (E14).

Thus, the morphological differences of CD133-positive cells in glioma C6 cultures and in cell cultures of fetal rat brain (E14) were detected. The decrease of CD133-positive cells in glioma C6 cells culture under the influence of neurogenic cells supernatant was shown.

\section{REFERENCES}

1. Angelastro JM, Lame MW. Overexpression of CD133 promotes drug resistance in C6 glioma cells. Mol. Cancer Res. 2010; 8(8):1105-1115.

2. Brescia P, Richichi Ch, Pehcci G. Current strategies for identification of glioma stem cells: Adequate or unsatisfactory? J. Oncol. 2012. Available: http://www.ncbi.nlm. nih.gov/pmc/articles/PMC3366252/pdf/J02012-376894.pdf.

3. Sanai N, Alvarez-Buylla A, Berger MS. Neural stem cells and the origin of gliomas. N. Engl. J. Med. 2005; 353(8):811-822.

4. Shervington A, Lu C, Shervington A. Expression of multidrug resistance genes in normal and cancer stem cells. Cancer Invest. 2008; 26(5):535-542.

5. Shen G, Shen F, Shi Z, et al. Identification of cancer stem-like cells in $\mathrm{C} 6$ glioma cell line and the limitation of current identification methods. In Vitro Cell Dev. Biol. Anim. 2008; 44(7):280-289.

6. Perez Castillo A, Aguilar-Morante D, Morales-Garcia JA, et al. Cancer stem cells and brain tumors. Clin. Transl. Oncol. 2008; 10(5):262-267.

7. Mizrak D, Brittan M, Alison MR. CD133 molecule of the moment. J. Pathol. 2008; 214(1):3-9.

8. Ahmed AU, Ulasov IV, Mercer RW, et al. Maintaining and loading neural stem cells for delivery of oncolytic adenovirus to brain tumors. Methods Mol. Biol. 2012; 797:97-109.

9. Khosh N, Brown CE, Aboody KS, et al. Contact and encirclement of glioma cells in vitro is an intrinsic behavior of a clonal human neural stem cell line. PLoS ONE. 2012. 7(12):e51859. Available: http://www.jourlib.org/paper/3003453

10. Aboody KS, Najbauer J, Metz MZ, et al. Neural Stem Cell-Mediated Enzyme/Prodrug Therapy for Glioma: Preclinical Studies. Sci. Transl. Med. 2013; 5(184):184-189.

11. Bovenberg MS, Degeling MH, Tannous BA. Advances in stem cell therapy against gliomas. Trends Mol. Med. 2013; 19(5):281-291.

12. Morshed RA, Gutova $M$, Juliano J, et al. Analysis of glioblastoma tumor coverage by oncolytic virus-loaded neural stem cells using MRI-based tracking and histological reconstruction. Cancer Gene Therapy. 2015; 22:55-61.

13. Stem cell therapeutics for cancer / Shah Kh.(ed.). Wiley Blackwell, 2013. 304 p.

14. Lisyany NI, Liubich LD. Doslidzhennja vplyvu supernatantu nejrogennyh klityn na puhlynoindukujuchu zdatnist' klityn gliomy 101.8 u shhuriv [Effects of the neurogenic cells supernatant on the tumor-inducing ability of glioma 101.8 in rats]. Klitynna ta organna transplantologija - Cell and Organ Transplantology. 2015; 3(1):52-61.

15. Liubich LD, Semenova VM, Stayno LP. Influence of rat progenitor neurogenic cells supernatant on glioma 101.8 cells in vitro. Biopolymers and Cell. 2015; 31(3):200-208

16. Bozhkova VP, Brezhestovsky PD, Zhuravlev VP, et al. Rukovodstvo po kul'tivirovaniju nervnoj tkani. Metody. Tehnika. Problemy [Guide culturing neural tissue. Methods. Equipment. Problems ] Moskva: Nauka - Moskow: Science, 1988. 317 p.

17. Chen R, Nishimura MC, Bumbaca SM, et al. A hierarchy of self-renewing tumor-initiating cell types in glioblastoma. Cancer Cell. 2010; 17(4):362-375.

18. Klassen HJ, Imfeld KL, Kirov II, et al. Expression of cytokines by multipotent neural progenitor cells. Cytokine. 2003; 22(3-4):101-106.

19. Liu J, Götherström C, Forsberg $M$, et al. Human neural stem/progenitor cells derived from embryonic stem cells and fetal nervous system present differences in immunogenicity and immunomodulatory potentials in vitro. Stem Cell Res. 2013; 10(3):325-337.

20. Chen $\mathrm{HC}$, Ma HI, Sytwu KH, et al. Neural stem cells secrete factors that promote auditory cell proliferation via a leukemia inhibitory factor signaling pathway. J. Neurosci. Res. 2010; 88(15):3308-3318.

21. Kaminska B, Kocyk M, Kijewska M. TGF beta signaling and its role in glioma pathogenesis. Adv.Exp.Med.Biol. 2013; 986:171-187.

22. Zhang J, Yang W, Zhao D, et al. Correlation between TSP-1, TGF- $\beta$ and PPAR- $\gamma$ expression levels and glioma microvascular density. Oncol. Lett. 2014; 7(1):95-100.

23. Dubrovska AM, Souchelnytskyi SS. Low-density microarray analysis of TGF $\beta 1$-dependent cell cycle regulation in human breast adenocarcinoma MCG7 cell line. Biopolymers and Cell. 2014; 30(2):107-117.

24. Binder DK, Scharfman HE. Brain-derived Neurotrophic Factor. Growth Factors. 2004; 22(3):123-131.

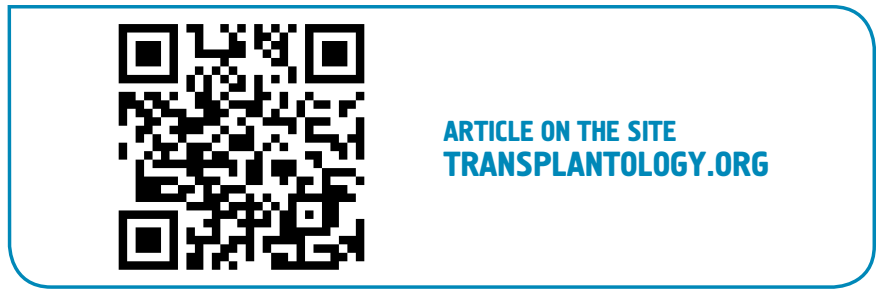

